\title{
The genus Keilbachia Mohrig from Mainland China, with descriptions of two new species (Diptera, Sciaridae)
}

\author{
Su-Jiong Zhang ${ }^{\dagger}$, Junhao Huang ${ }^{\ddagger}$, Hong Wu ${ }^{\S}$ Yi-ping Wang \\ College of Forestry and Biotechnology, Zhejiang A \& F University, Hangzhou 311300, China \\ † urn:lsid:zoobank.org:author:7E0BB886-08AA-4584-8710-63E8EFA7BAA9 \\ $\ddagger$ urn:lsid:zoobank.org:author:49A80164-AA3E-4A47-ABE6-B4E112291488 \\ § urn:lsid:zoobank.org:author:4D9B3A38-09F7-46CB-B9A9-9A540951C496 \\ | urn:lsid:zoobank.org:author:D8E7A259-C421-4F85-BB02-B78179DBABC5 \\ Corresponding author: Hong Wu (wuh8977@sohu.com)
}

Academic editor: Chris Thompson | Received 3 December 2009 | Accepted 2 July 2010 | Published 30 July 2010

urn:lsid:zoobank.org:pub:E1C5E2DD-2EDF-4DA7-83DA-519B37D2E1F1

Citation: Zhang S-J, Huang J, Wu H, Wang Y-P (2010) The genus Keilbachia Mohrig from Mainland China, with descriptions of two new species (Diptera, Sciaridae). ZooKeys 52: 47-56. doi: 10.3897/zookeys.52.362

\begin{abstract}
Seven species of Keilbachia Mohrig are recognized, and among them, two new species, K. subacumina Wu \& Zhang, sp. n. and $K$. fengyangensis Wu \& Zhang, sp. n. are described and illustrated. Five species, $K$. orthonema, K. flagrispina, K. demssia, K. oligonema and K. acumina are reported for the first time from China. A key to the 15 Chinese species of this genus is also provided.
\end{abstract}

\section{Keywords}

Diptera, Sciaridae, Keilbachia, new species, Mainland China, Oriental Region

\section{Introduction}

The genus Keilbachia was firstly proposed for $K$. nepalensis Mohrig from Nepal (Mohrig and Martens 1987: 483). Subsequently, additional species are described from the Oriental, Palaearctic, Neotropical, and Australian Regions. Menzel and Martens (1995) described two species from Nepal-Himalaya. Mohrig et al. (1999) described

Copyright S.J. Zhang et al. This is an open access article distributed under the terms of the Creative Commons Attribution License, which permits unrestricted use, distribution, and reproduction in any medium, provided the original author and source are credited. 
four species from Nepal. Menzel and Mohrig (2000) transferred two Palaearctic species to Keilbachia. Mohrig (2004) described one new species from Papua New Guinea. Mohrig et al. (2004) described one new species from Dominica. Vilkamaa et al. (2006) described eight new species from Myanmar. Hippa and Vilkamaa (2007a, b) described 15 species from Oriental regions and reassigned one Nearctic species to the genus. Rudzinski (2008) described five new species from Taiwan. Vilkamaa et al. (2009) reviewed the genus, adding 11 new species from Oriental Region and one more species by combination. Therefore, 52 species of the genus have been recorded until now, mostly from the Oriental Region, including eight species that occur in Taiwan.

In this study, seven species of Keilbachia are recognized from Mainland China. Among them, two new species, fengyangensis and subacumina are described and illustrated. Five species, flagrispina, demssia, orthonema, oligonema and acumina are reported for the first time from China. An additional 8 species of Keilbachia are known from Taiwan China: adjuncta Vilkamaa, Menzel \& Hippa (2009: 5); ferrata (Hippa \& Vilkamaa 1994: 50, Camptochaeta); grandiosa Rudzinski (2008: 347); praedicata Rudzinski (2008: 348); profana Rudzinski (2008: 349); sasakwawai (Mohrig \& Menzel 1992: 21, Corynoptera); subferrata Rudzinski (2008: 346) and ulcerate Rudzinski (2008: 349).

\section{Materials and methods}

All specimens were collected by sweeping in the field and preserved in $75 \%$ ethanol. They were mounted on glass slides in xylol-based Canada balsam after clearing in creosote. The heads of specimens from Yunnan province were bleached in $10 \% \mathrm{NaOH}$ for about 24 hours at room temperature. The specimens were observed and measured under a Nikon SMZ1500 stereoscopic microscope. The illustrations were prepared under a Nikon Eclipse 50i optical microscope, with an attached drawing tube. The terminology follows Hippa and Vilkamaa (2007b). The length of 4th flagellomere is taken from the apex of the neck to the base of the body. The wing length is the straight distance from the humeral angle to the apical angle. The body length is the straight distance between apex of head and apex of hypopygium. The type specimens designated in the present study are deposited in the collection of the Laboratory of Forest Protection, Zhejiang A \& F University, Hangzhou, Zhejiang province, China [ZAFU].

\section{Results and discussion}

\section{Key to Chinese Species of Keilbachia (Based on Males)}

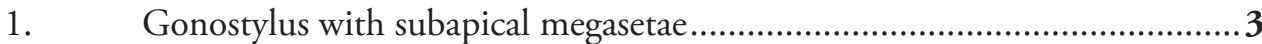

- Gonostylus with no subapical megasetae.................................................. 2

2. Gonostylus with one mesial megaseta ..........................................praedicata 
- Gonostylus with two mesial megasetae.

oligonema

3. Gonostylus with one or two subapical megasetae ………..........................5

- Gonostylus with three or more subapical megasetae.................................... 4

4. Gonostylus with one mesial megaseta on middle and another one at the base of gonostylus.

profana

Gonostylus with only one mesial megaseta at the base of gonostylus

5. Gonostylus with two subapical megasetae. adjuncta Gonostylus with two subapical megasetae.

6. Mesial megaseta of gonostylus short, shorter than maximal width of gonostylus. orthonema

- Mesial megaseta of gonostylus long, at least as long as maximal width of gonostylus. .7

7. Subapical megasetae of gonostylus close to each other, both at apical fourth of gonostylus.....

- Subapical megasetae of gonostylus widely apart, basal most one at apical third or apical half of gonostylus.

8. Tegmen modified, slightly broader subbasally than subapically .... sasakawai

- $\quad$ Tegmen simple, much broader subbasally than subapically

9. Basal body of mesial megaseta of gonostylus long and slender...... subferrata

- Basal body of mesial megaseta of gonostylus short and stout... 10

10. Basalmost subapical megasetae at apical half of gonostylus (Fig. 5)

subacumina

- Basalmost subapical megasetae at apical third of gonostylus (Fig. 6)

11. Subapical megasetae of gonostylus subequal in size acumina

- Subapical megasetae of gonostylus not equal in size 13

12. Apicalmost subapical megaseta of gonostylus slender 12

- Apicalmost subapical megaseta of gonostylus stout

13. Apex of gonostylus rounded and broad ferrata

- Apex of gonostylus pointed and grandiosa

14. Mesial megaseta of gonostylus long and strongly curved (Fig. 10) flagrispina

- Mesial megaseta short and slightly curved

fengyangensis

demissa

\section{Keilbachia flagrispina}

Keilbachia flagrispina Mohrig, in Mohrig, Röschmann \& Rulik 1999: 198.

Diagnostic characters (Male). Body length $1.64-1.71 \mathrm{~mm}$; wing length $1.36-1.41 \mathrm{~mm}$. Eye bridge 3-4 facets wide. Length/width of $4^{\text {th }}$ flagellomere 2.19-2.32.

Anterior pronotum with 5-6 setae. Episternum 1 with 3-4 setae. c/w $0.69-0.72, R_{1} / R$ 0.71-0.76, r-m with one seta. 
The mesial megaseta on gonostylus very long and curved, nearly three times as long as the width of gonostylus. The basal body of mesial megaseta is not distinct. Tegmen simple, much broader subbasally than subapically.

Specimens examined. China, Yunnan, Baoshan, Mts. Gaoligongshan, 24²9.729'N, 98 46.074'E, sweep-net 11.V.2009. 4 males, Man-Man Wang [SM00878-00880, SM00882] (ZAFU); 3 males, Su-Jiong, Zhang [SM00886, SM00902-00903] (ZAFU).

Distribution. China (Yunnan), Myammar, Nepal.

Biology. Unknown.

Remarks. This species is new to China, which was firstly described from Nepal, based on two males. It is similar to $K$. ferrata (Hippa \& Vilkamaa, 1994) in having two subapical megaseta and a long mesial megaseta, but $K$. flagrispina can be separated by the mesial megaseta very long and strongly curved, and two subapical megaseta subequal in length on gonostylus. The materials examined from China do not show distinct variation, but we found the Chinese specimens are much smaller in body length, which is $1.64-1.71 \mathrm{~mm}$, while $2.5 \mathrm{~mm}$ in Nepal materials.

\section{Keilbachia demissa Vilkamaa, Komarova \& Hippa}

Keilbachia demissa Vilkamaa, Komarova \& Hippa, 2006: 45.

Diagnostic characters (Male). Body length 1.73-1.78 mm; wing length 1.47-1.49 mm. Eye bridge 3-4 facets wide. Prefrons with 10-12 setae. Length/width of 4th flagellomere 2.17-2.41.

Anterior pronotum with 5-6 setae. Episternum 1 with 7-8 setae.

Length of spur/width of fore tibia 1.20-1.27. Length of metatibia /length of tho$\operatorname{rax} 1.05-1.12$.

c/w 0.62-0.64, R /R 0.52-0.56, r-m with no setae.

The mesial megaseta on gonostylus long and slightly curved, basal body long. Tegmen simple, much broader subbasally than subapically.

Specimens examined. China, Yunnan, Baoshan, Mts. Gaoligongshan, $24^{\circ} 49.729^{\prime} \mathrm{N}$, 98 46.074'E, sweep-net, 11.V.2009. 6 males, Su-Jiong Zhang [SM00856, SM00859, SM00862, SM00869, SM00875, SM00881] (ZAFU); 1 male, Man-Man Wang [SM00888] (ZAFU).

Distribution. China (Yunnan), Burma.

Biology. Unknown.

Remarks. This species is new to China, which was firstly described from Burma based on seven males. It is similar to K. scutica Vilkamaa, Komarova \& Hippa, 2006 and $K$. flagrispina by the tegmen broadest subbasally (Mohrig et al. 1999; Vilkamaa, Komarova and Hippa 2006). But it differs in having the mesial megaseta of the gonostylus much shorter and less strongly curved. The materials examined in China do not show distinct intraspecies variation, but the apical of gonostylus in the specimens SM00881 and SM00856 is more attenuated and curved than the other specimens. 


\section{Keilbachia orthonema Hippa \& Vilkamaa}

Keilbachia orthonema Hippa \& Vilkamaa, 2007b: 66.

Diagnostic characters (Male). Body length 1.76-1.82 mm; wing length $1.35-1.37 \mathrm{~mm}$. Eye bridge 3-4 facets wide. Prefrons with 9-11 setae. Length/width of $4^{\text {th }}$ flagellomere $2.47-2.53$.

Anterior pronotum with 4-5 setae. Episternum 1 with 5-6 setae.

Length of spur/width of protibia 1.76-1.81.

c/w $0.79-0.82, \mathrm{R}_{1} / \mathrm{R} 0.71-0.73$, r-m with $0-1$ seta.

The mesial megaseta on gonostylus short and straight, slightly longer than its basal body. Two slender megasetae at apical forth of gonostylus. Tegmen slightly broader subbasally than subapically.

Specimens examined. China, Yunnan, Yingjiang, Tongbiguan, $24^{\circ} 36.004^{\prime} \mathrm{N}$, 97³9.139'E, sweep-net, 20.V.2009. 6 males, Su-Jiong Zhang [SM00657-00658, SM00663-00664, SM00670, SM00680] (ZAFU); 3 males, Man-Man Wang [SM00653, SM00666-00667] (ZAFU).

Distribution. China (Yunnan), Malaysia.

Biology. Unknown.

Remarks. This species is new to China, which was firstly described from Sabah, Malaysia, based on two male specimens. It is similar to K. apprima Vilkamaa, Komarova \& Hippa, 2006 from Vietnam by sharing a short mesial megaseta (Hippa \& Vilkamaa 2007b), but K. orthonema can be distinguished by mesial megaseta longer and much less curved, and apical forth of gonostulus with two slender megasetae. The Chinese material examined does not show distinct intraspecies variation, but the two megasetae at the apical forth of the gonostylus are stronger than in Malaysia materials, judging from the figures prepared by Hippa and Vilkamaa (2007b). What's more, length/width of 4th flagellomere is 2.47-2.53, smaller than in Malaysia materials, which is about 3 times as long as wide.

\section{Keilbachia acumina Vilkamaa, Menzel \& Hippa}

Keilbachia acumina Vilkamaa, Menzel \& Hippa, 2009: 4.

Diagnostic characters (Male). Body length 1.51-1.57 mm; wing length 1.25-1.28 mm. Eye bridge three facets wide. Prefrons with 3-5 setae. Length/width of 4th flagellomere 2.35-2.71.

Anterior pronotum with 3-4 setae. Episternum 1 with 4-5 setae.

Length of spur/width of protibia 1.55-1.57.

c/w $0.64-0.65, \mathrm{R}_{1} / \mathrm{R} 0.72-0.75$, r-m with no setae.

Gonostylus with two megasetae widely apart, one at subapical and stout, the other at apical third and slender (Fig. 6). Basal third of gonostylus excavated, with a long and 
strongly curved subbasal mesial megaseta on broad basal body. Tegmen simple, much broader subbasally than subapically, with sparsely placed teeth.

Specimens examined. 1 male, China, Zhejiang, Linan, Mt. Xijingshan, $30^{\circ} 23^{\prime} \mathrm{N}$, $119^{\circ} 72^{\prime} \mathrm{E}$, sweep-net, 21.VI.2008, Su-Jiong Zhang [SM00018] (ZAFU); 1 male, China, Zhejiang, Lishui, Mt. Jiulongshan, $28^{\circ} 59^{\prime} \mathrm{N}, 119^{\circ} 25^{\prime} \mathrm{E}$, sweep-net, 10.X.2008, SuJiong Zhang [SM00114] (ZAFU); 1 male, Yunnan, Tengchong, Shaba, Mt. Tiantaishan, $25^{\circ} 24.524^{\prime} \mathrm{N}, 98^{\circ} 42.735^{\prime} \mathrm{E}$, sweep-net, 13.V.2009, Su-Jiong Zhang [SM00933] (ZAFU).

Distribution. China (Zhejiang, Yunnan), Japan.

Biology. Unknown.

Remarks. The species is similar to K. subferrata Rudzinski and K. ferrata (Hippa \& Vilkamaa) by having a rather long subbasal mesial megaseta on a large basal body, But it can be distinguished from $K$. subferrata by the smaller mesial megaseta in a more apical position (Vilkamaa et al. 2009), and differs from $K$. ferrata by having the basal body slightly smaller, and the socket of the apical megaseta more distinct (Vilkamaa et al. 2009). Vilkamma et al. (2009) mentioned $K$. acumina shows intraspecies variation in the structure of the gonostylus and the length of the flagellomeres. The variations are also examined in the Chinese materials, that the position of basalmost subapical megasetae varies in the apical third of gonostylus and the length of the 4th flagellomere among 67.63-87.58 um.

\section{Keilbachia subacumina Wu \& Zhang, sp. n.}

urn:lsid:zoobank.org:act:878985DF-CC83-4052-9486-06582BA13734

Figs 1-5

Description (Male). Body length 1.81-2.32 mm; wing length 1.49-1.52 mm.

Color. Head, thorax and abdomen brown; antenna, palpus, coxae, and hypopygium yellowish-brown; leg yellow; wing fumose.

Head (Figs 1, 2). Eye bridge 3-4 facets wide. Prefrons with 5-6 setae, clypeus with 0-1 seta. Palpus three-segmented. Basal segment with one seta, with a narrow sensory pit, 2nd segment with 4-6 setae, 3rd segment with 6-7 setae. Length/width of 4th flagellomere 2.74-2.79.

Thorax. Anterior pronotum with 5-6 setae. Episternum 1 with 6-7 setae.

Legs. Apex of protibia (Fig. 3). Length of spur/width of protibia 1.79-1.83. Length of profemur/length of protibia $0.76-0.79$. Length of metatibia /length of thorax 1.23-1.31.

Wings. Width/length 0.44-0.49.

c/w 0.71-0.77, R/R 0.96-0.98. r-m with 1-2 setae.

Abdomen. Sternite 8 with $10-11$ setae. Gonostylus and gonocoxa subequal in length. Gonostylus with two megasetae widely apart, one at apex and stout, the other at apical half of gonostylus and slender. Basal third of gonostylus excavated, with a long and strongly curved mesial megaseta on broad basal body. Tegmen simple, much broader subbasally than subapically, with sparsely placed teeth. (Figs 4, 5).

Specimens examined. Holotype, male. China, Zhejiang, Linan, Mt. Xijingshan, $30^{\circ} 23^{\prime} \mathrm{N}, 119^{\circ} 72^{\prime} \mathrm{E}$, sweep-net, 21.VI.2008, Su-Jiong Zhang [SM00025] (ZAFU). 


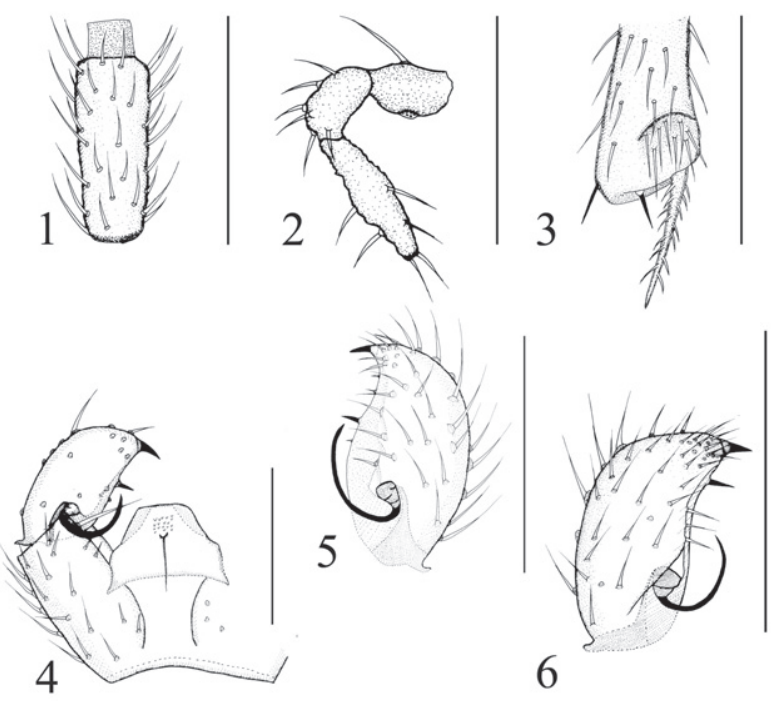

Figures I-6. I-5, Keilbachia subacumina, male. I 4th flagellomere, lateral view $\mathbf{2}$ palpus, lateral view $\mathbf{3}$ apex of protibia, prolateral view $\mathbf{4}$ part of hypopygium, ventral view $\mathbf{5}$ gonostylus, ventral view. $\mathbf{6}$ Keilbachia acumina, male, gonostylus, ventral view. Scale bar $=0.1 \mathrm{~mm}$.

Paratypes. 2 males, same data as holotype [SM00018, SM00024] (ZAFU); 5 males, same data as holotype but 19.VII.2008 [SM00057-00061] (ZAFU). China, Zhejiang, Lishui, Mt. Fengyangshan, $28^{\circ} 04^{\prime} \mathrm{N}, 119^{\circ} 08^{\prime}$ E. sweep-net, 3 males, 11.VIII.2008, Sheng-Long Liu [SM00282] (ZAFU); 1 male, 24.VIII.2008, Sheng-Long Liu [SM00231-00233] (ZAFU); 1 male, 01.VIII.2008, Xiao-Ling Niu [SM00306] (ZAFU). 1 male, China, Zhejiang, Lishui, Mt. Jiulongshan, 28 $59^{\prime} \mathrm{N}, 119^{\circ} 25^{\prime} \mathrm{E}$, sweep-net, 10.X.2008, Su-Jiong Zhang, [SM00114] (ZAFU).

Biology. Unknown.

Remarks. This species is very similar to $K$. acumina in the structure of the hypopygium (Fig. 5, 6), but K. subacumina can be distinguished by having the apex of gonostylus broader, and the stouter and shorter basalmost megaseta at the apical half of the gonostylus. What's more, the anterior pronotum bears 5-6 setae in K. subacumina while 3-4 setae in K. acumi$n a$, and the r-m nervation of the wing with 1-2 setae in $K$. subacumina while bare in $K$. acumina. The structure of the hypopygium in the new species does not show distinct intraspecies variation. The species is named after its similarity to $K$. acumina. This epithet is an adjective.

\section{Keilbachia fengyangensis Wu \& Zhang, sp. n.} urn:lsid:zoobank.org:act:3BA818B3-5B93-495A-9117-BC26DDE09CF8 Figs $7-11$

Description (Male). Body length 2.31-2.48 mm; wing length 1.92-1.94 mm. 
Color. Head, thorax and abdomen brown; antenna, palpus, coxae, legs and hypopygium yellowish-brown; wing fumose.

Head (Fig. 7, 8). Eye bridge 3-4 facets wide. Prefrons with 7-8 setae, clypeus with no setae. Palpus three-segmented. Basal segment with one seta, with wide sensory pit, 2nd segment with 4-6 setae, 3rd segment with 7-8 setae. Length/width of 4th flagellomere 2.91-2.94.

Thorax. Anterior pronotum with 4 setae, episternum 1 with 5-6 setae.

Legs. Apex of protibia (Fig. 9). Length of spur/width of protibia 1.45-1.49. Length of profemur/length of protibia $0.65-0.68$. Length of metatibia/length of tho$\operatorname{rax} 1.03-1.11$.

Wings. Width/length $0.45-0.47$.

c/w 0.62-0.69; $\mathrm{R}_{1} / \mathrm{R}$ 0.83-0.91. r-m with one seta.

Abdomen. Sternite 8 with nine setae. Gonostylus longer than gonocoxa, slightly curved, with two slender apical and subapical megaseta. The basal third of gonostylus with a long and curved mesial megaseta on a narrow and short basal body. Tegmen higher than broad, with sparse placed teeth (Fig. 10, 11).

Specimens examined. Holotype, male. China, Zhejiang, Lishui, Mt. Fengyangshan, $28^{\circ} 04^{\prime} \mathrm{N}, 119^{\circ} 08^{\prime} \mathrm{E}$, sweep-net, 26.IV.2008, Sheng-Long Liu [SM00342] (ZAFU). Paratypes. 2 males, same data as holotype [SM00335, SM00338] (ZAFU); 1 male, same data as holotype but 19.IV.2008 [SM00346] (ZAFU).

Biology. Unknown.

Remarks. This species is found only from Mt. Fengyangshan, Zhejiang. It is similar to $K$. demissa and $K$. flagrispina by having a long mesial megaseta, but it can be distinguished from $K$. demissa by having the megaseta of the gonostylus longer and more curved, and the tegmen with no distinct basolateral. The new species can be distinguished from $K$. flagrispina by the apex of gonostylus distinct attenuated, and the mesial megaseta shorter and not strongly curved. The species is named after its type locality (Mt. Fengyangshan).

\section{Keilbachia oligonema Hippa \& Vilkamaa}

Keilbachia oligonema Hippa \& Vilkamaa, 2007a: 45.

Diagnostic characters (Male). Body length $1.71 \mathrm{~mm}$; wing length $1.66 \mathrm{~mm}$.

Eye bridge four facets wide. Prefrons with nine setae. Length/width of 4th flagellomere 3.30 .

Anterior pronotum with five setae, episternum 1 with three setae.

Apex of protibia. Length of spur/width of protibia 1.48.

Width/length 0.40 ,

c/w $0.73, \mathrm{R}_{1} / \mathrm{R}$ 0.87. $\mathrm{r}-\mathrm{m}$ with no setae.

Gonocoxa ventrally with a slight indication of an intercoxal lobe. Gonostylus nearly as long as gonocoxa, with no apical and subapical megaseta. The basal third of gonostylus excavated, with two long and curved mesial megaseta on a broad basal body. Tegmen simple, much broader subbasally than subapically. 


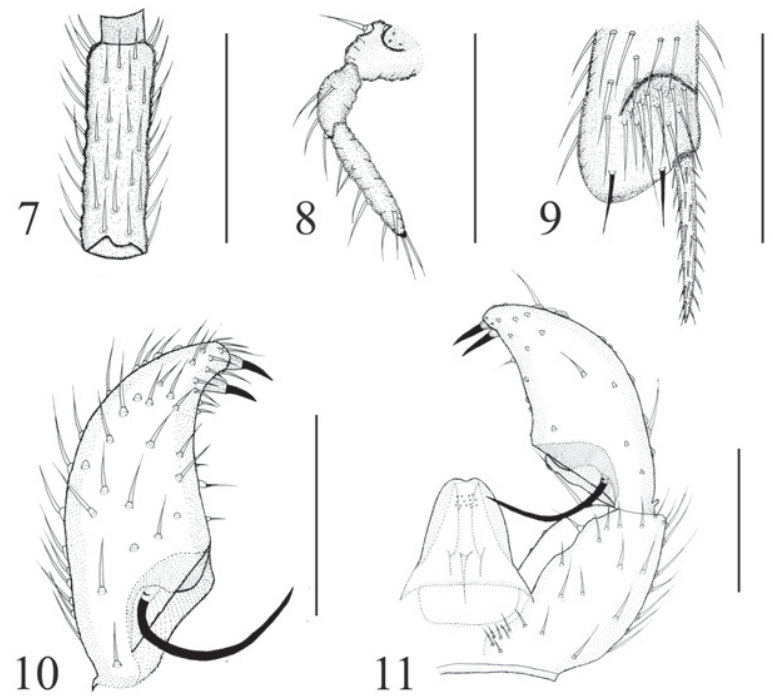

Figsures 7-II. Keilbachia fengyangensis, male. 7 4th flagellomere, lateral view 8 palpus, lateral view $\mathbf{9}$ apex of protibia, prolateral view $\mathbf{I} \mathbf{0}$ gonostylus, ventral view I I part of hypopygium, ventral view. Scale bar $=0.1 \mathrm{~mm}$.

Specimens examined. 1 male. China, Yunnan, Tengchong, Dahaoping, $98^{\circ} 45^{\prime} \mathrm{N}$, $24^{\circ} 55^{\prime} \mathrm{E}$, sweep-net, 22.V.2009, Man-Man Wang, [SM00757] (ZAFU).

Distribution. China (Yunnan), Burma.

Biology. Unknown.

Remarks. The gonostylus of K. oligonema Hippa \& Vilkamaa, 2007 with two long and curved mesial megaseta, and without apical and subapical megaseta. It is different from all the other species in the group of flagria, which has more than one mesial megaseta on the gonostylus. K. oligonema is unique in having different characters in width of the eye bridge, setosity of sternite 8 , and the ventral intercoxal area of the hypopygium between the holotype and two additional specimens, from which the authors suspected they may represent two different species (Hippa \& Vilkamaa 2007a). The same as the holotype of K. oligonema, the Chinese material has gonocoxa ventrally with a slight indication of an intercoxal lobe, but its four facets wide eye bridge, and six setose sternite 8 are similar to the additional materials.

\section{Acknowledgements}

We wish to express our sincere thanks to Dr. Heikki Hippa (Swedish Museum of Natural History, Stockholm), Dr. Pekka Vilkamaa (Finnish Museum of Natural History, Helsinki), Dr. Frank Menzel (Senckenberg Deutsches Entomologisches Institut, Müncheberg) and Dr. Werner Mohrig (Poseritz, Germany) for their kind cooperation 
and generous help. Special thanks are given to Dr. Hippa for his advice to improve the text. We also thank the collectors of the materials examined, Manman Wang from Zhejiang University and Shenglong Liu from Fengyangshan National Nature Reserve. This study was supported by NSFC grant 30870334.

\section{References}

Hippa H, Vilkamaa P (2007a) The flagria group of Keilbachia Mohrig (Diptera, Sciaridae) in a biodiversity hot spot: nine new sympatric species from Kambaiti, Myanmar. Zootaxa 1556: 31-50.

Hippa H, Vilkamaa P (2007b) New species and records of Keilbachia Mohrig (Diptera, Sciaridae) from the Oriental region. Zootaxa 1622: 57-68.

Hippa H, Vilkamaa P (1994) The genus Camptochaeta gen. n. (Diptera, Sciaridae). Acta Zoologica Fennica 194: 1-85.

Menzel F, Martens J (1995) Die Sciaridae (Diptera, Nematocera) des Nepal-Himalaya. Teil I. Die blütenbesuchenden Trauermücken an Aronstabgewächsen der Gattung Arisaema (Araceae Juss.). Studia dipterologica 2: 97-129.

Menzel F, Mohrig W (2000) Revision der paläarktischen Trauermücken (Diptera: Sciaridae). Studia dipterologica Supplement 6: 1-761.

Mohrig W (2004) Die Trauermücken (Diptera: Sciaridae) von Papua-Neuguinea. Teil II Gattungen Scythropochroa, Cratyna, Pseudozygomma, Epidapus, Hyperlasion, Corynoptera, Keilbachia, Scatopsciara, Pelliciplanta gen. nov. und Pseudozygomma gen. nov. Studia Dipterologica 11: 129-174.

Mohrig W, Martens J (1987) Sciaridae aus dem Nepal-Himalaya (Insecta: Diptera). Courier Forschungsinstitut Senckenberg 93: 481-490.

Mohrig W, Menzel F, Kozánek M (1992) Neue Traüermucken (Dipter, Sciaridae) aus NordKorea und Japan. Dipterological Research 3: 17-30.

Mohrig W, Röschmann F, Rulik B (1999) New sciarid flies (Diptera, Sciaridae) from Nepal. Deutsche Entomologische Zeitschrift (Neue Folge) 46: 189-201.

Mohrig W, Röschmann F, Rulik B (2004) The fauna of sciarid flies from the Dominican Republic (Diptera, Sciaridae). Beiträge zur Entomologie 54: 267-331.

Rudzinski H (2008) Beiträge zur Trauermückenfauna Taiwans. Teil V: Gattungen Dichopygina, Camptochaeta, Corynoptera und Keilbachia. (Diptera Nematocera: Sciaridae). Entomofauna 23: 321-360.

Vilkamaa P, Komarova L, Hippa H (2006). The genus Keilbachia Mohrig (Diptera: Sciaridae) in a biodiversity hot spot: new sympatric species from Kambaiti, Burma. Zootaxa 1123: 39-55.

Vilkamaa P, Menzel F, Hippa H (2009) Review of the genus Keilbachia Mohrig (Diptera: Sciaridae), with the description of eleven new species. Zootaxa 2272: 1-20. 